\title{
Experimental Study on Fire Behaviour in Room following the Disposition of Openings
}

\author{
Fidel Meskéoulé Vondou, ${ }^{1,2}$ Claude Valery Ngayihi Abbe $\mathbb{D D}^{1,2}{ }^{1,2}$ Justin Tégawendé Zaida, ${ }^{3}$ \\ Philippe Onguene Mvogo, ${ }^{4}$ and Ruben Mouangue ${ }^{5}{ }^{5}$
}

${ }^{1}$ Faculty of Industrial Engineering, University of Douala, Douala, Cameroon

${ }^{2}$ Laboratory of Research in Energy, Material, Modelling and Methods, University of Douala, Douala, Cameroon

${ }^{3}$ Department of Physics, University of Fada, Fada-Ngourma, Gourma Province, Burkina Faso

${ }^{4}$ Department of Physics, Faculty of Science, University of Ngaoundere, Ngaoundere, Cameroon

${ }^{5}$ Department of Energy Engineering, IUT, University of Ngaoundere, Ngaoundere, Cameroon

Correspondence should be addressed to Ruben Mouangue; r_mouangue@yahoo.fr

Received 12 November 2019; Revised 31 December 2019; Accepted 10 January 2020; Published 1 February 2020

Academic Editor: Michael A. Delichatsios

Copyright (C) 2020 Fidel Meskéoulé Vondou et al. This is an open access article distributed under the Creative Commons Attribution License, which permits unrestricted use, distribution, and reproduction in any medium, provided the original work is properly cited.

\begin{abstract}
Many experiments have been done by authors to study the influence of the natural ventilation through openings on fire behaviour in compartments. It has been revealed that fire will be influenced by the size of existing openings which can be an open window, an open door, or both of them. Concerning the last case, the literature does not give any information about the impact of the arrangement of these openings on the behaviour of fire. The present paper aims then to carry out a comparative study of the disposition of the window compared to the door, on the behaviour of fire in a compartment. To achieve that objective, fire experiments were conducted in a reduced scale room of dimensions $1.20 \mathrm{~m} \times 1.20 \mathrm{~m} \times 1.02 \mathrm{~m}$, which can be modulated into two configurations. The first one named "PFC configuration" is the case where the open door and the open window are in nonopposite walls. The second one named "PFO configuration" is the case where these both openings are in opposite walls. After having performed several fire tests in both configurations using the same amount of diesel fuel as fire source, results revealed that the fuel burns faster in the PFC configuration compared to that in the PFO configuration. This is due to a global mass loss rate of $2.93 \times 10^{-4} \mathrm{~kg} \cdot \mathrm{s}^{-1}$ against $2.62 \times 10^{-4} \mathrm{~kg} \cdot \mathrm{s}^{-1}$, respectively. Beyond a difference of $20^{\circ} \mathrm{C}$ observed on the maximal temperature of burned gases located at ceiling, results also revealed the production of ghosting flames in the PFO configuration.
\end{abstract}

\section{Introduction}

Fire occurring in an enclosure uses combustibles which burn in the presence of oxygen of surrounding air. Duration and heat release rate of such fire depend mainly on the nature of fuel and on the level of natural ventilation in the enclosure [1-3]. Propagation of fire is function of heat energy released over time, which consequently induces an increase of temperature in the enclosure. The release of that heat during fire generates complex phenomena. The most prominent of them is the plume which reflects the upward flow of gases observed above the fire source and is governed by buoyancy forces induced by a difference in density between hot gases coming from the combustion of fuel and the surrounding cool air [4]. Indeed, these hot gases rising up create a depression around the fire source and provoke aspiration of surrounding air toward the source. This allows maintaining the fire ongoing until the exhaustion of fuel. During fire in closed or semienclosed environments, transient dangerous phenomena may also occur. Among them, the most feared by firefighters is backdraft [5-8]. Defined as a spontaneous explosion of smokes saturated in unburned pyrolysis gases, the backdraft occurs when some specific conditions are met notably with a sudden influx of air in a confined room in fire.

Accurate description of fire in compartment with confined ventilation is thus of practical interest in fire safety 
engineering. Researchers are interested in experimentation more than the numerical simulation of fire behaviour, in view to better understand its mechanisms. Indeed, generally considered as ventilation-controlled fires, compartment fires with confined ventilation have been extensively investigated through theoretical, experimental, and numerical studies [9-13]. Besides the likelihood for backdraft to occur, all these studies revealed other specificities about the behaviour of fire in a confined compartment such as the production of ghosting flames, flames ejections, and spill plume [14-17]. Beside fires in confined compartments, previous studies have mainly dealt with fires in naturally ventilation compartments. In fact, fire behaviour with natural ventilation is generally classified by using the opening or ventilation factor $[15,18]$. Widely implied in compartment fires with natural ventilation, that factor takes into account the dimensions of openings relatively to the total size of compartment in fire [19]. Through that ventilation factor, other parameters influencing the behaviour of fire can be estimated such as the mass flow rates of incoming cool air or outgoing hot gases leaving the room through openings [20-22].

From the previous analysis, development of compartment fire depends on several factors of which the most considered are the energy rate released by the fire source, the availability, and nature of fuel, as well as the size of the compartment in fire. Focused on compartment fires with natural ventilation, the objective of the present paper is to carry out a comparative study on the impact of the disposition of the window compared to the door on the behaviour of fire. On the other hand, it will be about answering the question if there are some differences on the behaviour of fire when the door and the window are opposite and when they are not. The first part will focus on the experimental device designed for the performing of real fire tests and the second part will focus on results observed during experiments.

\section{Material and Methods}

2.1. Experimental Device and Data Collection. The experimental device in which experiments were conducted is a compartment model of dimensions $L \times W \times H: 1.20 \mathrm{~m} \times 1.20 \mathrm{~m} \times 1.02 \mathrm{~m}$ (Figure 1). Made with plywood panels of thickness $10 \mathrm{~cm}$, that model includes an open door of size $0.70 \mathrm{~m} \times 0.37 \mathrm{~m}$ on its front wall and two open windows of dimensions $0.40 \mathrm{~m} \times 0.40 \mathrm{~m}$ (Figures 2(a) and 2(b)). One of these windows is on the right wall, while the other is on the rear wall. For the purpose of studying experimentally the influence on fire, of the disposition of the window according to the door, the experimental domain has been exploited under two configurations. The first configuration named "PFC configuration" is the one of which only the door and the right window are opened (Figure 3(a)) and the second configuration named "PFO configuration" is the one of which only the door and the rear window are opened (Figure 3(b)). Placed on the center of the room floor, the fire source is a cylindrical pan of diameter $d=0.175 \mathrm{~m}$ and height $h=0.10 \mathrm{~m}$, in which the combustible to be used as flames generator is introduced.

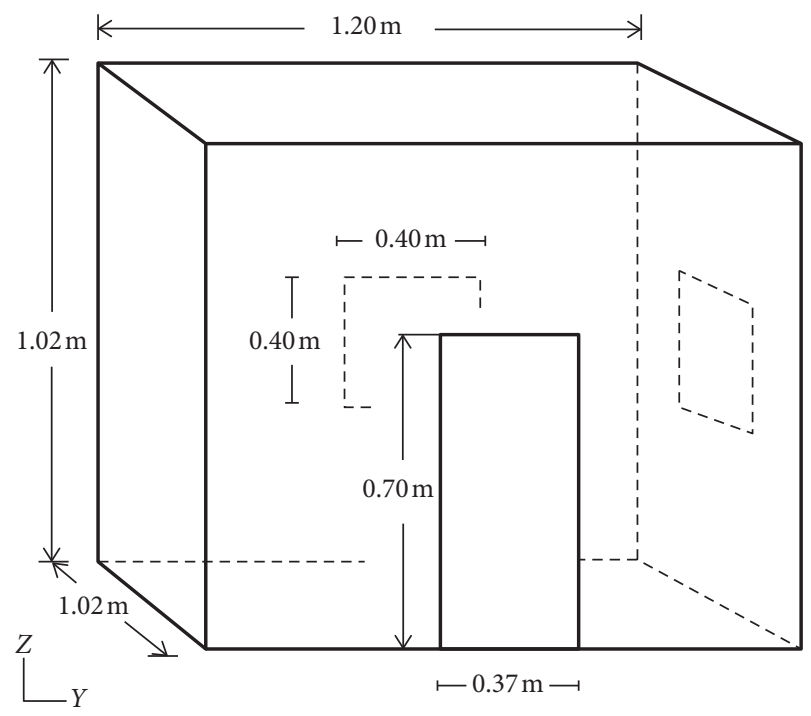

FIgURE 1: Geometry of the experimental domain including one door and two windows.

Collection of data during experiments is done using a set of measuring instruments of which the main is the data collection system called Agilent 34970A which enables to measure and record temperature according to a given step time (Figure 4). In this data acquisition equipment, the 40channel multiplexer is inserted on which an array of 40 sensors can be connected. In the present study, only 12 channels are exploited and then connected with 12 thermocouples (Figure 5). Seven thermocouples of type K were set along the height of the domain (TV1-TV7) so as to measure the temperature at different altitudes inside the room. Four thermocouples of type N (TH-TH4) were set at the ceiling of the room so as to measure the temperature of burned gases. And the last one (THF) with a long probe has been set directly above the fire source in order to measure the temperature of flames. Figure 6 presents the assembling of the apparatus with a computer which enables us to directly visualize the evolving of parameters during experiment. Table 1 gives the $3 \mathrm{D}$ coordinates of the measuring points in the room where the probes of thermocouples have been placed. In view to describe the fire behaviour in each configuration, fire experiments are conducted in both configurations using the same amount of diesel fuel $(0.135 \mathrm{~kg})$ in the pan as combustible so as to have the similar initial conditions in both cases.

The experimental protocol consists in preheating the amount of diesel fuel put in the pan until a temperature of $60^{\circ} \mathrm{C}$ is reached and then igniting fire. The data acquisition system is simultaneously launched for the measuring and recording of parameters after each 10 seconds. That action is done until the fuel in the pan is completely burned.

2.2. Statistical Analysis of Experiments. Fire tests on each configuration were repeated 4 times and only the average of data obtained from these repetitions, calculated according to (1), has been represented and interpreted. The repeatability 


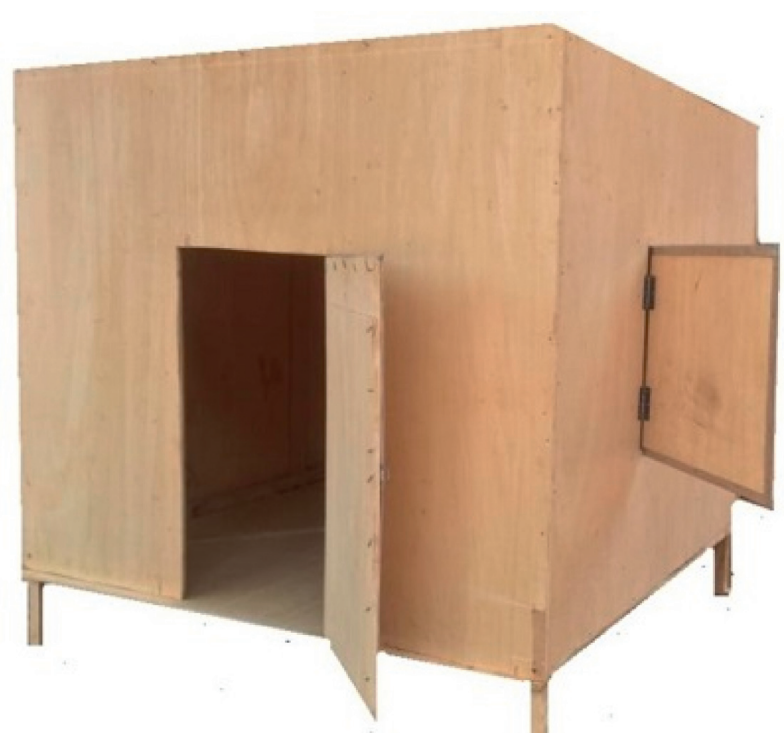

(a)

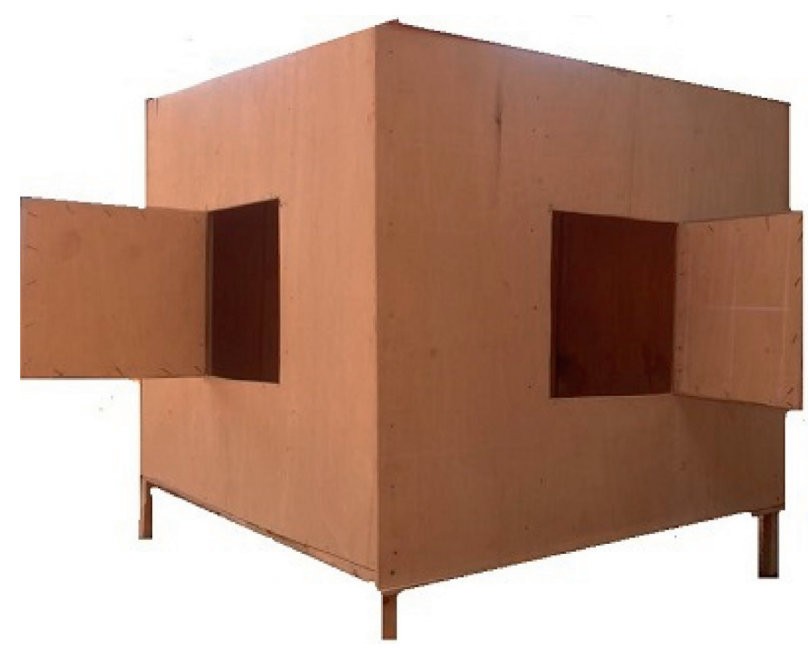

(b)

Figure 2: (a) Front view of the experimental domain. (b) Rear view of the experimental domain.

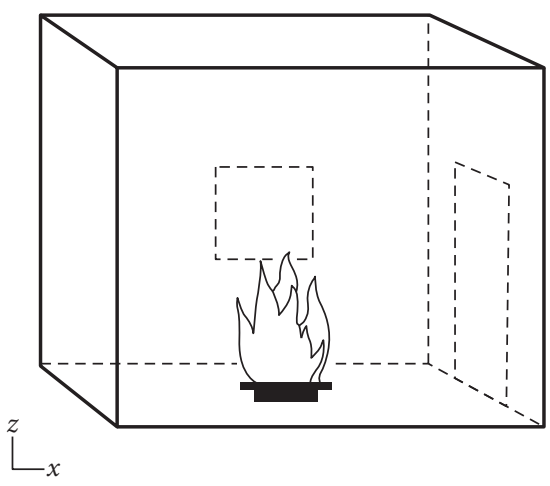

(a)

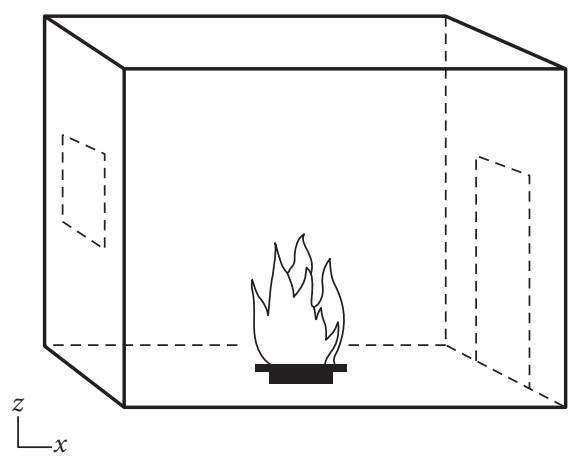

(b)

FIgure 3: (a) Presentation of the domain under the PFC configuration. (b) Presentation of the domain under the PFO configuration.

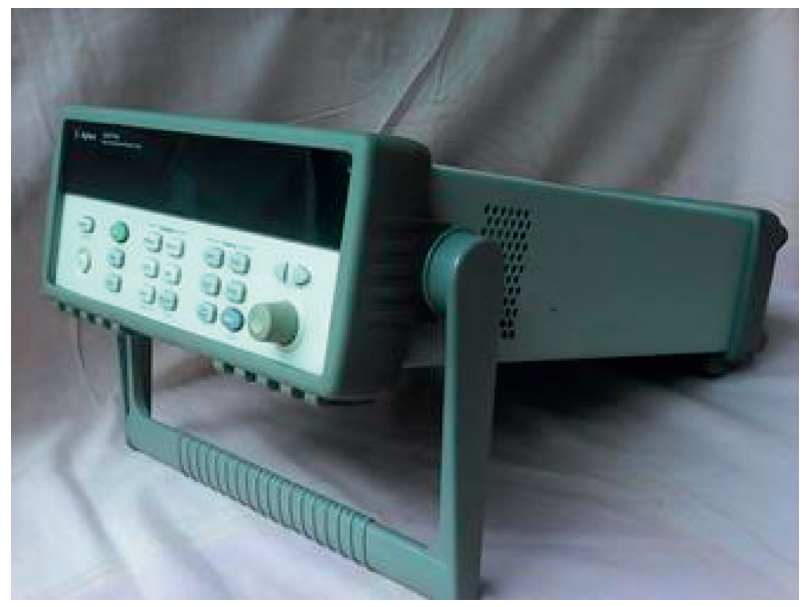

FIGURE 4: Data acquisition system named Agilent 34970A.

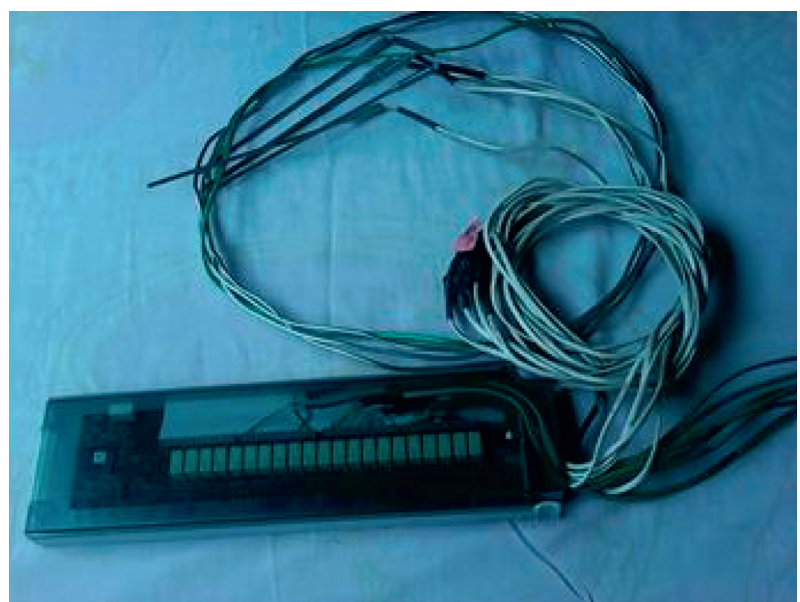

FIGURE 5: Array of 12 thermocouples connected to the 40-channel multiplexer. 


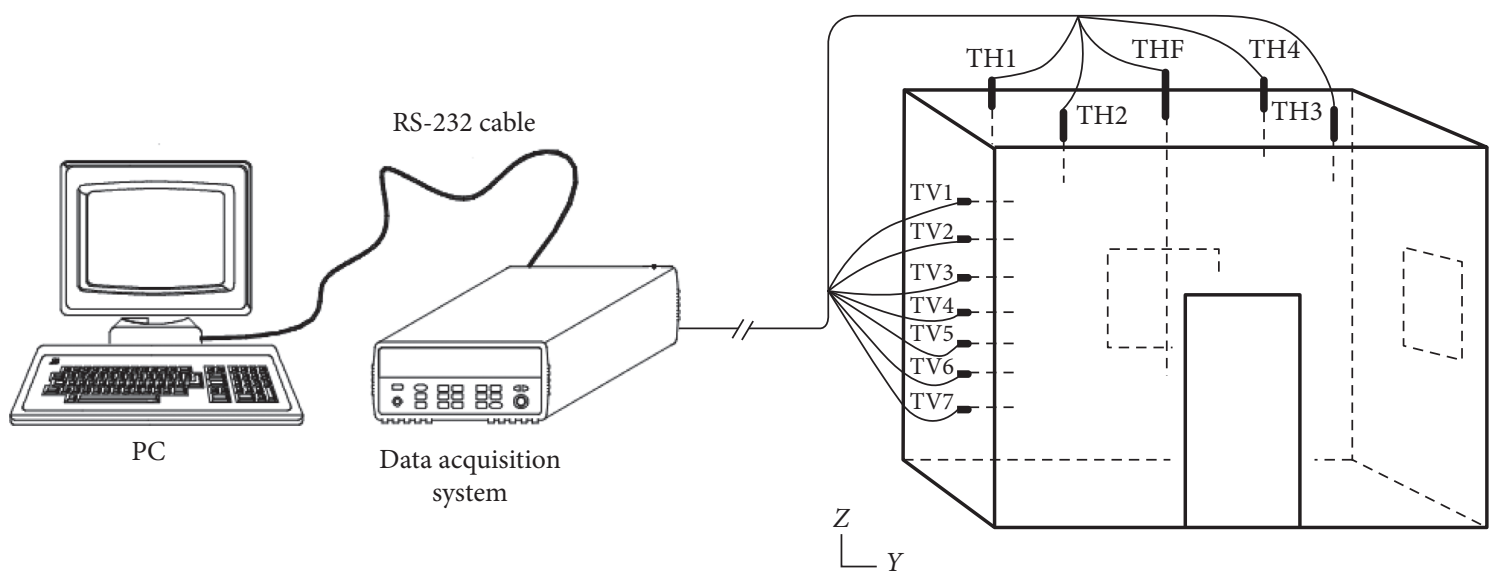

FIgURE 6: Experimental diagram illustrating the locations of thermocouples in the experimental room.

TABLE 1: Coordinates of the thermocouples installed in the experimental domain.

\begin{tabular}{ccccccccccccc}
\hline & TV1 & TV2 & TV3 & TV4 & TV5 & TV6 & TV7 & TH1 & TH2 & TH3 & TH4 & THF \\
\hline$X$ & 0.58 & 0.58 & 0.58 & 0.58 & 0.58 & 0.58 & 0.58 & 0.30 & 0.90 & 0.90 & 0.30 & 0.60 \\
$Y$ & 0.10 & 0.10 & 0.1 & 0.10 & 0.10 & 0.10 & 0.10 & 0.30 & 0.30 & 0.90 & 0.90 & 0.60 \\
$Z$ & 0.95 & 0.80 & 0.65 & 0.55 & 0.45 & 0.35 & 0.25 & 0.85 & 0.85 & 0.85 & 0.85 & 0.40 \\
\hline
\end{tabular}

of experiments was checked thanks to Cochran's test [23]. Indeed the application of this test consists in checking if variances of repetitions are homogeneous. This is done by comparing the statistic value $C_{\text {Test }}$ with the existing value $C_{\text {Table }}$ of Cochran's table. The calculation of the statistic value is given by (2), where $V_{i}$, given by (3), is the variance of test $i$ and $V_{\max }$ is the maximal variance among variances of various repetitions. If the calculated statistic value is less than the value of the table, then the variances are all homogeneous. That means that experiments are repeating and have the same results with a level of confidence of $95 \%$. However, if the calculated value is more than the table's value, experiments are not repeating. Results cannot be exploited and compared because the repeatability of tests is not valid.

$$
\begin{aligned}
\bar{X}_{i} & =\frac{1}{4} \sum_{j=1}^{4} x_{i j}, \\
V_{j} & =\frac{1}{n_{j}-1} \sum\left(x_{i j}-\bar{x}_{j}\right)^{2}, \\
C_{\text {Test }} & =\frac{V_{\max }}{V_{1}+V_{2}+\cdots+V_{k}} .
\end{aligned}
$$

2.3. Theoretical Approach of Compartment Fire. The main consequence in fire process is the production of heat which is manifested by high temperatures. Fire growth in compartment can be adequately described by a single energy equation including a single representative temperature. An idealized energy balance is written for a fire plume and hot layer, through the following equation [24-27]:

$$
\rho w c_{p} \frac{\mathrm{d} T}{\mathrm{~d} t}=G(T, t)-L(T, t),
$$

where $\rho$ is the density and $w$ is the volume of the fluid in the layer, $c_{p}$ is the specific heat of the layer gases, $T$ is its temperature, $t$ is time, $L$ represents the energy losses through openings and solid boundary surfaces, and $G$ represents the rate of energy produced by the fire source and transferred to the hot layer. During compartment fire, the rate energy generated by the source depends widely on the effective heat of combustion of the fuel and mostly on the air supplying the source. Fire will then behave according to the draught of air crossing the source in the compartment, which will depend on the disposition of existing openings.

\section{Results and Discussion}

3.1. Progress of Fire Tests. During fire tests in each configuration, some observations about flame have been noted. Concerning the behaviour of fire in the PFO room, Figures $7(\mathrm{a})-7$ (c) present three sequential pictures of fire with a time step of $10 \mathrm{sec}$. It can be observed during these $20 \mathrm{sec}$ that the flame is too unstable with a lot of ghosting flames which fly till the ceiling of the room. That instability is due to the fact that the window is opposite to the door and it exists between both openings, a crossing current of exterior air which leads to the cutting of the main flame. However, when both openings are not opposite, there are no more ghosting flames. Flames are persistent (Figures 8(a)-8(c)) and describe a rotary movement around the vertical axis of the source.

3.2. Repeatability of Tests. In view to bring out the repeatability of each experiment carried out, curves showing the 


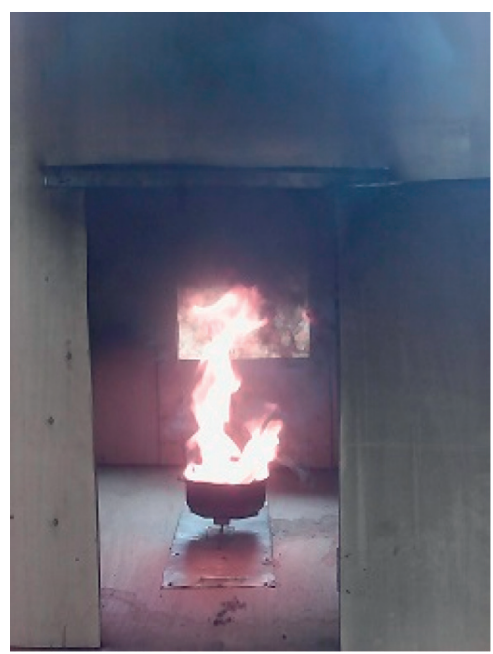

(a)

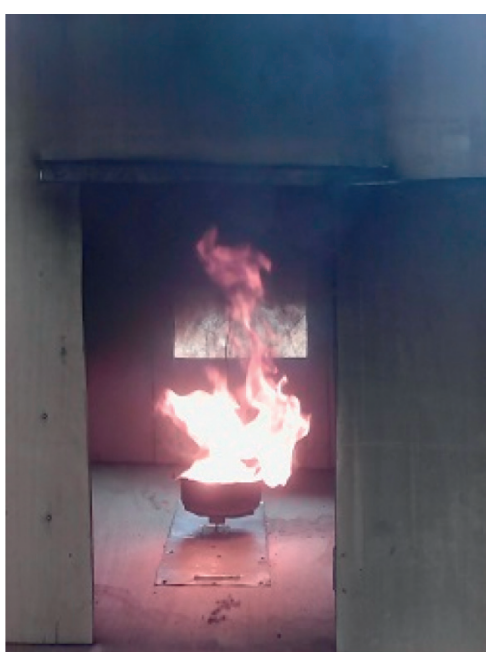

(b)

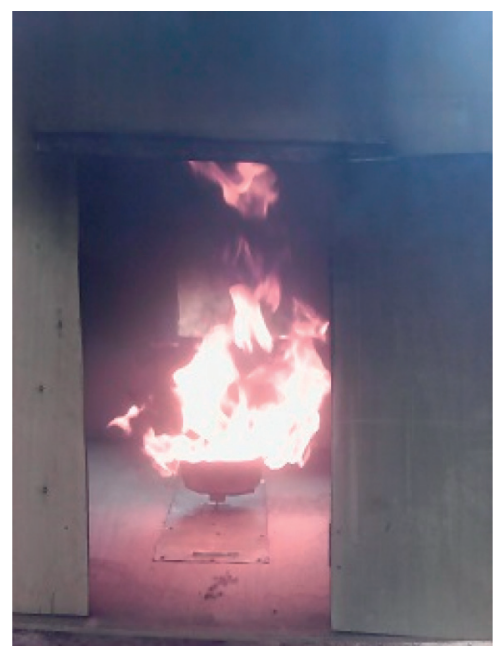

(c)

Figure 7: (a) Fire in the PFO configuration at time $t_{0}$. (b) Fire in the PFO configuration at time $t_{0}+10 \mathrm{~s}$. (c) Fire in the PFO configuration at time $t_{0}+20 \mathrm{~s}$.

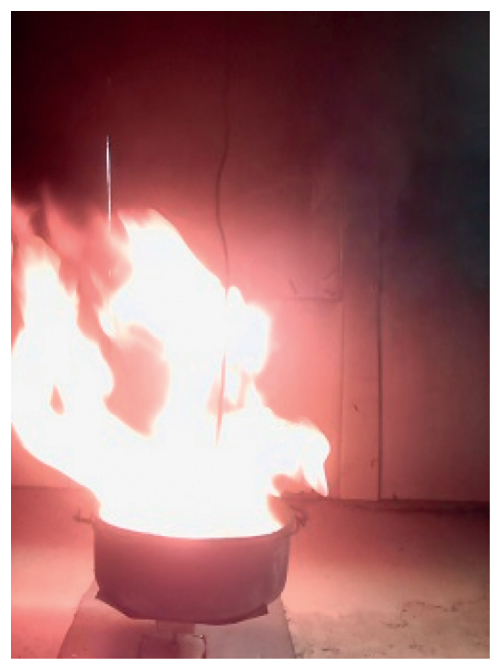

(a)

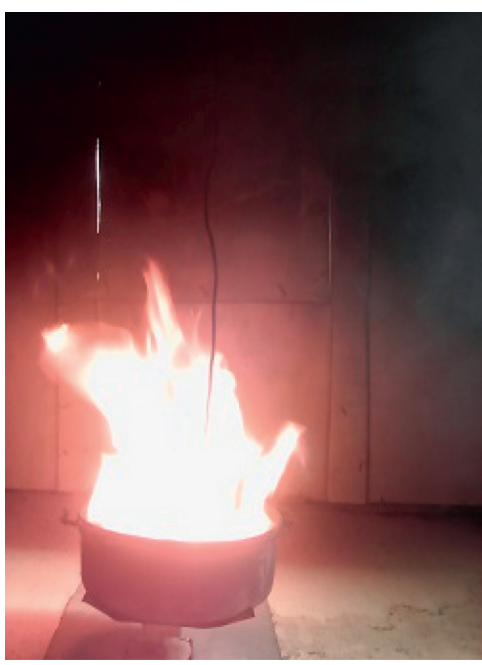

(b)

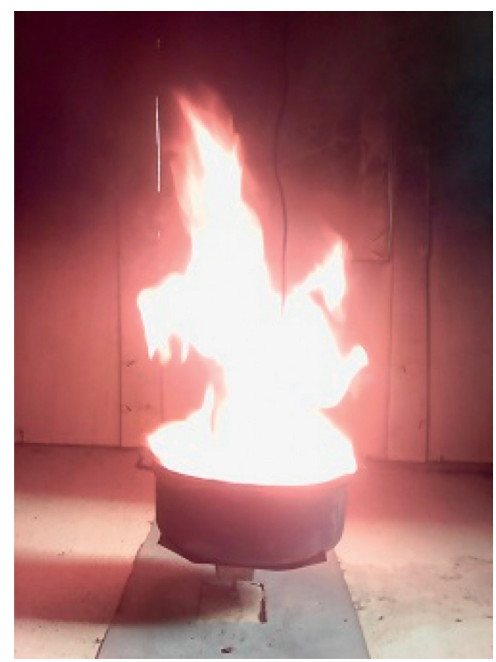

(c)

Figure 8: (a) Fire in the PFC configuration at time $t_{0} \mathrm{~s}$. (b) Fire in the PFC configuration at time $t_{0}+10 \mathrm{~s}$. (c) Fire in the PFC configuration at time $t_{0}+20 \mathrm{~s}$.

change of burned gases temperature over time of various repeated tests of some under ceiling thermocouples have been plotted. For the four repeated tests made on the PFO configuration, Figures 9(a) and 9(b) present the temperature profiles of thermocouples TH1 and TH3. Following a visual aspect, similarity between both figures can be observed on the shape of curves on which the three phases of the development of compartment fire are noted, namely, growth, full development, and decline phase. It can also be observed that the average temperature reached by burned gases accumulated at ceiling is almost equal for both thermocouples. Concerning fire tests in the PFC configuration (Figures 10(a) and 10(b)), similar observations are made concerning the three phases of fire, shape of temperature curves, and the average temperature reached by burned gases accumulated at ceiling. All these observations are a proof that there is not any significant influence on experiments.

In order to prove statistically that repeatability, an application of the Cochran test on data of these reference thermocouples (TH1 and TH3) has demonstrated the repeatability of each experiment performed on each configuration. Table 2 presents a comparison between the calculated statistical values $\left(C_{\text {Test }}\right)$ and values of the Cochran table $\left(C_{\text {Table }}\right)$. It comes out from this comparative table that 


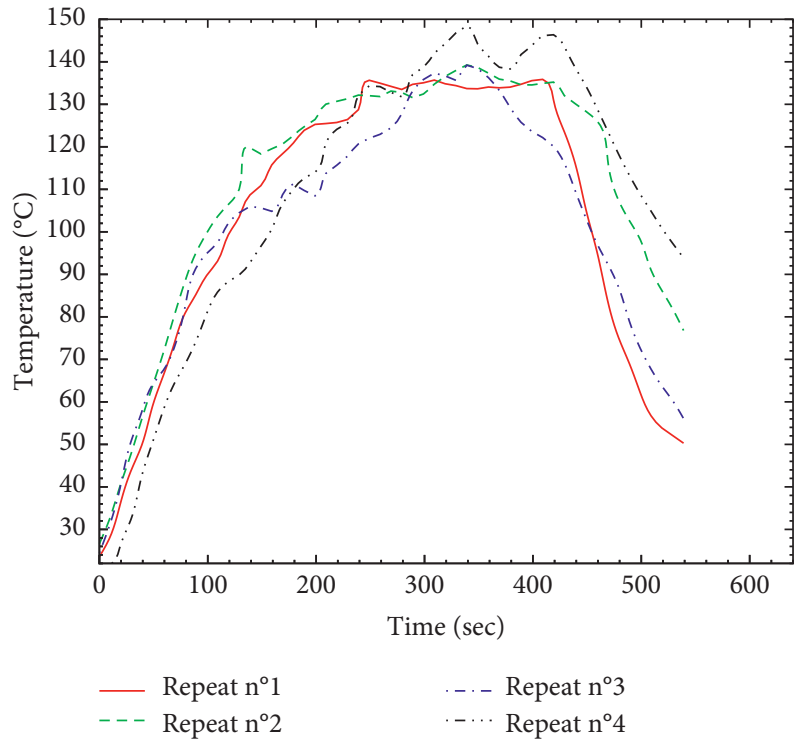

(a)

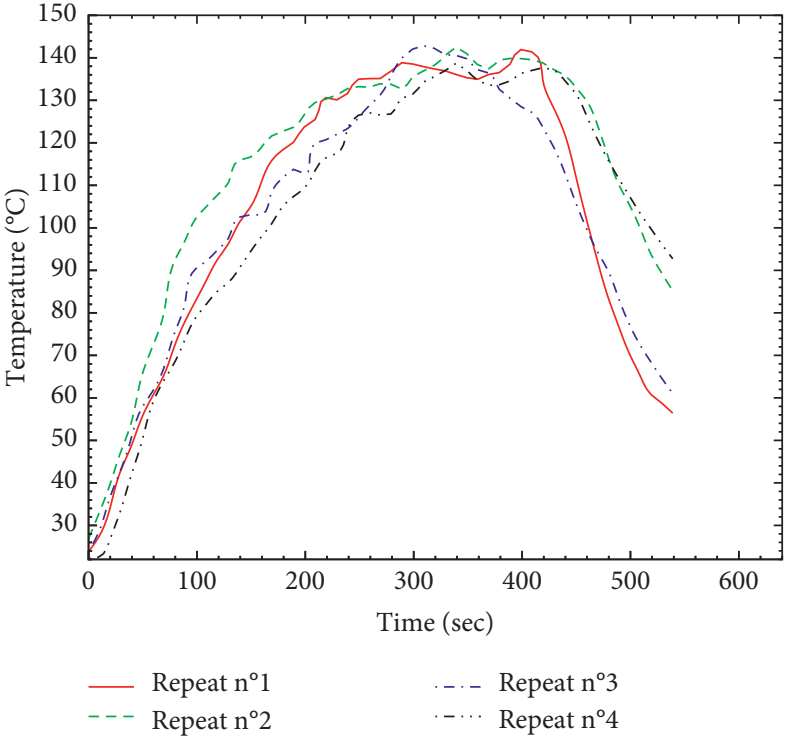

(b)

Figure 9: (a) Temperature profiles of TH1 plotted during tests in the PFC configuration. (b) Temperature profiles of TH3 plotted during tests in the PFC configuration.

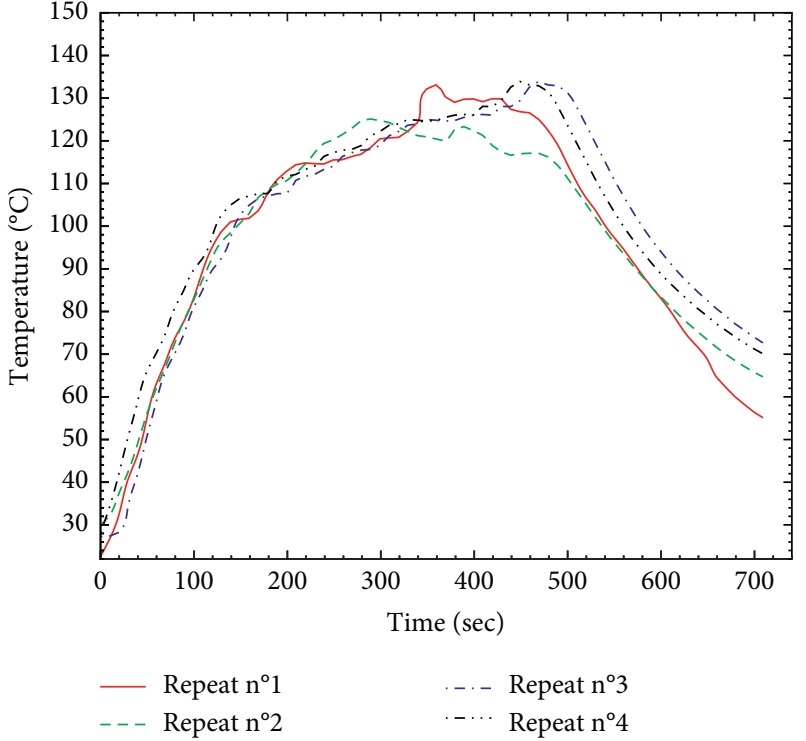

(a)

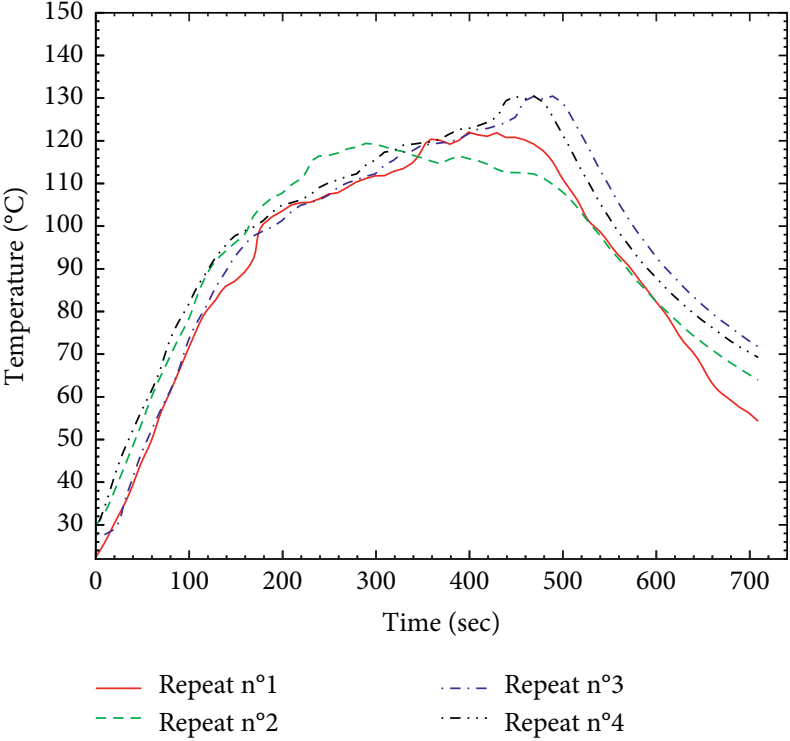

(b)

FIgURE 10: (a) Temperature profiles of TH1 plotted during tests in the PFO configuration. (b) Temperature profiles of TH3 plotted during tests in the PFO configuration.

the calculated values are all lower than values of the Cochran table, proving that the variances of repetitions are all homogeneous. Following that statistical analysis, it can be concluded that experiments are repeated at a level of confidence of $95 \%$.

3.3. Influence on the Temperature of the Flame and of the Plume. Temperature in the persistent zone of the flame was followed during experiments on both configurations. It appears that the disposition of the window compared to the door does not have any significant influence on the temperature of flame because both configurations have almost an equal level of aeration. Figure 11 presents the curve of the average temperature of flame as a function of time. According to the literature, compartment fires evolve following three stages which are growth, full development, and decay phase [28]. That figure points up these phases and especially the prompt time during which fire jumps from one stage to another. In both configurations, flames took 
TABLE 2: Results obtained from Cochran's test.

\begin{tabular}{lcccl}
\hline & Thermocouple & $C_{\text {Test }}$ & $C_{\text {Table }}$ & Comparison \\
\hline \multirow{2}{*}{ PFC configuration } & TH1 & 0,285 & 0,332 & $C_{\text {Test }}<C_{\text {Table }}$ \\
& TH3 & 0,289 & 0,332 & $C_{\text {Test }}<C_{\text {Table }}$ \\
\multirow{3}{*}{ PFO configuration } & TH1 & 0,301 & 0,347 & $C_{\text {Test }}<C_{\text {Table }}$ \\
& TH3 & 0,287 & 0,347 & $C_{\text {Test }}<C_{\text {Table }}$
\end{tabular}

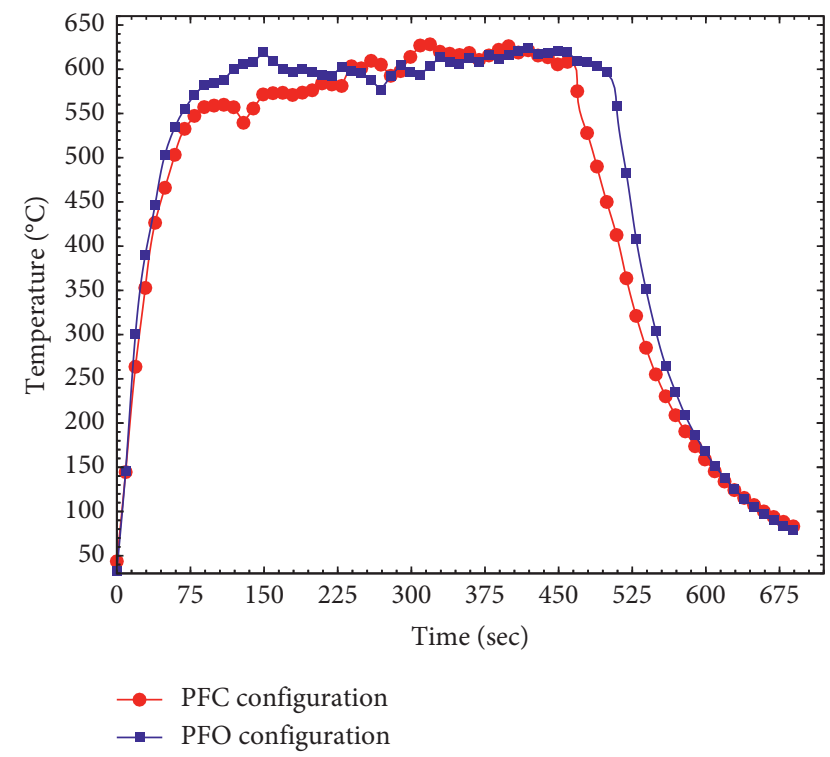

FIGURE 11: Confrontation between curves of flame temperature of $\mathrm{PFO}$ and PFC configurations.

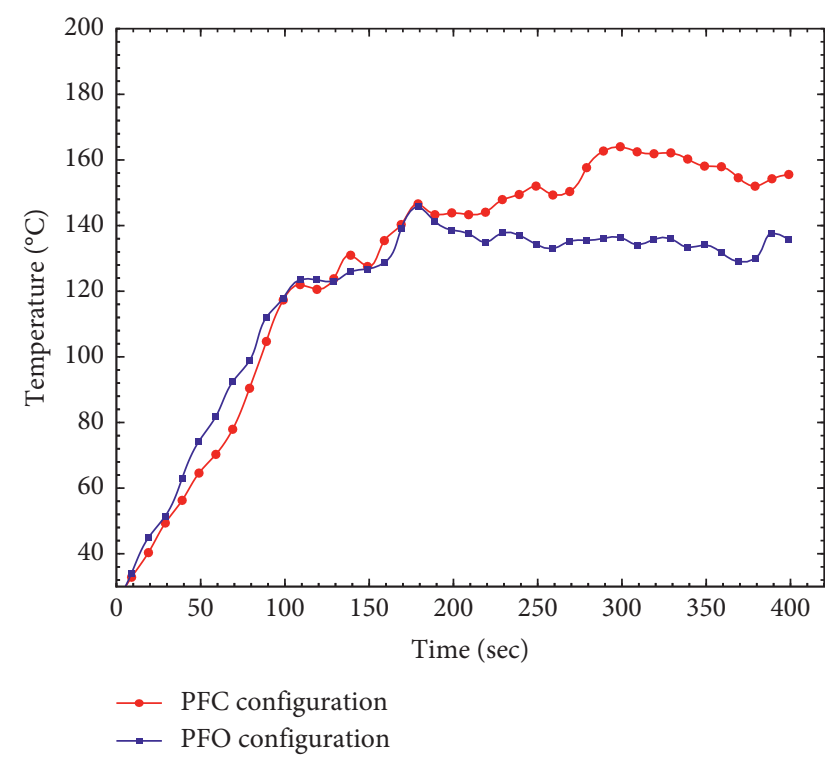

Figure 12: Confrontation between curves of hot gases temperature in the plume of PFO and PFC configurations.

approximately 75 seconds to become fully developed. However, there is a little difference on the second-phase duration, which is illustrated by the fact that, after ignition, fire burned for 460 seconds on the PFC configuration, while it burned for 515 seconds on the PFO configuration. It can also be observed on that figure that the maximal temperature

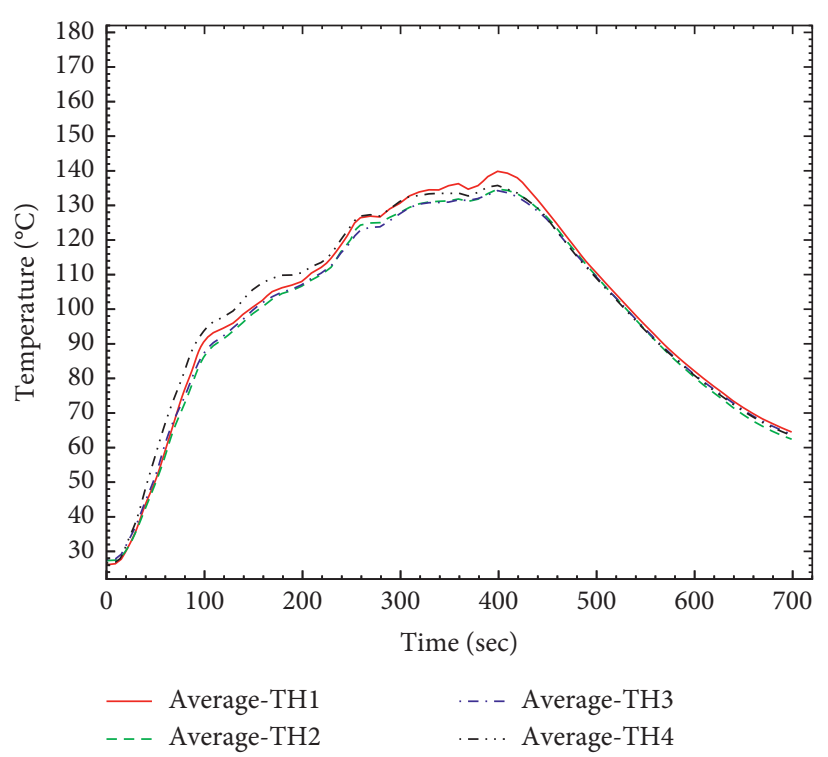

FIgURE 13: Temperature of hot gases under ceiling of the PFC configuration.

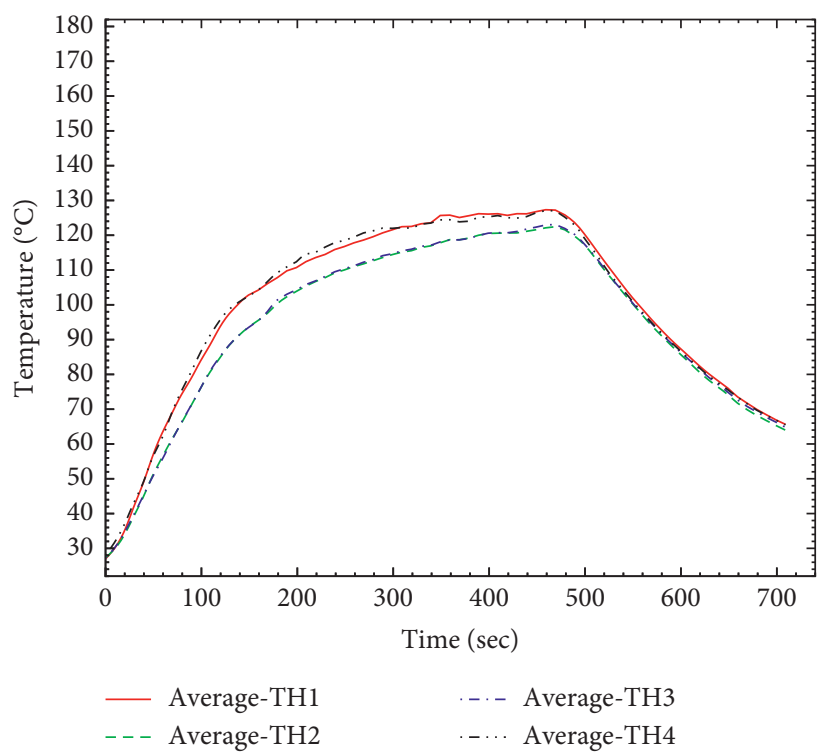

Figure 14: Temperature of hot gases under ceiling of the PFO configuration.

reached by flames is almost the same and equal to $600^{\circ} \mathrm{C}$ for both case studies.

A similar analysis of the temperature of hot gases in the plume (stream of hot gases rising above the flame) reveals that, during full development phase of fire, the fraction of energy carried by hot gases is higher in the PFC configuration than in the PFO configuration. Indeed, one part of heat generated by combustion is retransmitted to fuel allowing its evaporation, and the remaining part is transmitted to the environment by radiation and by convection to the ascending gases of plume. The opposite disposition of window thus contributes to the reduction of the convective energy of hot gases because of the cooling due to the air flow passing through the flame during fire. That flow of air is 


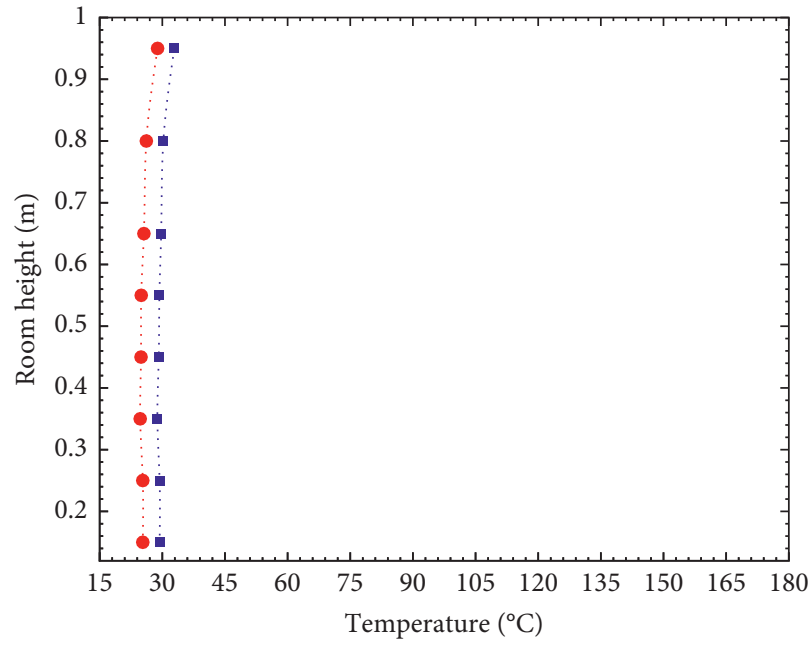

- $\quad$ PFC (time $=5 \mathrm{~s})$

-. $\operatorname{PFO}($ time $=5 \mathrm{~s})$

(a)

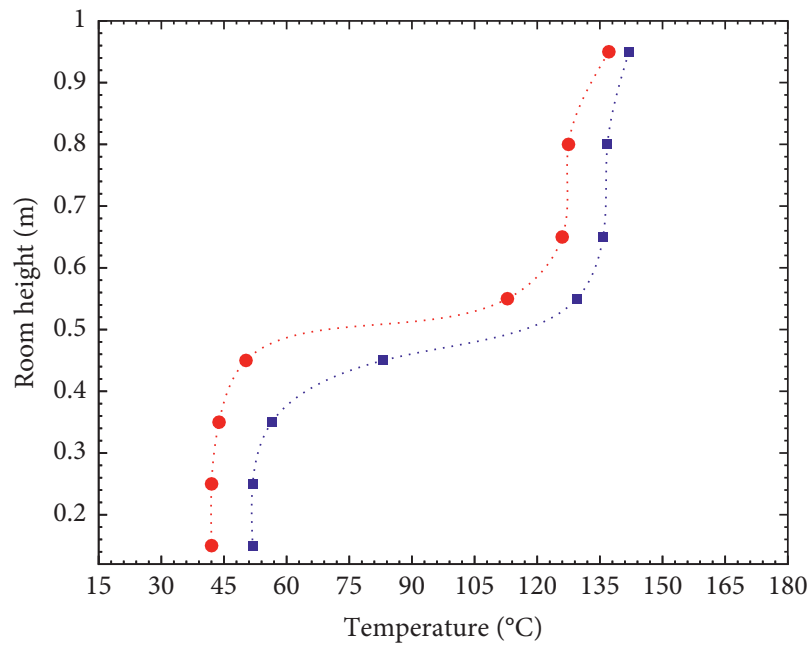

-. $\quad$ PFC (time $=250 \mathrm{~s}$ )

a. $\quad$ PFO (time $=250 \mathrm{~s})$

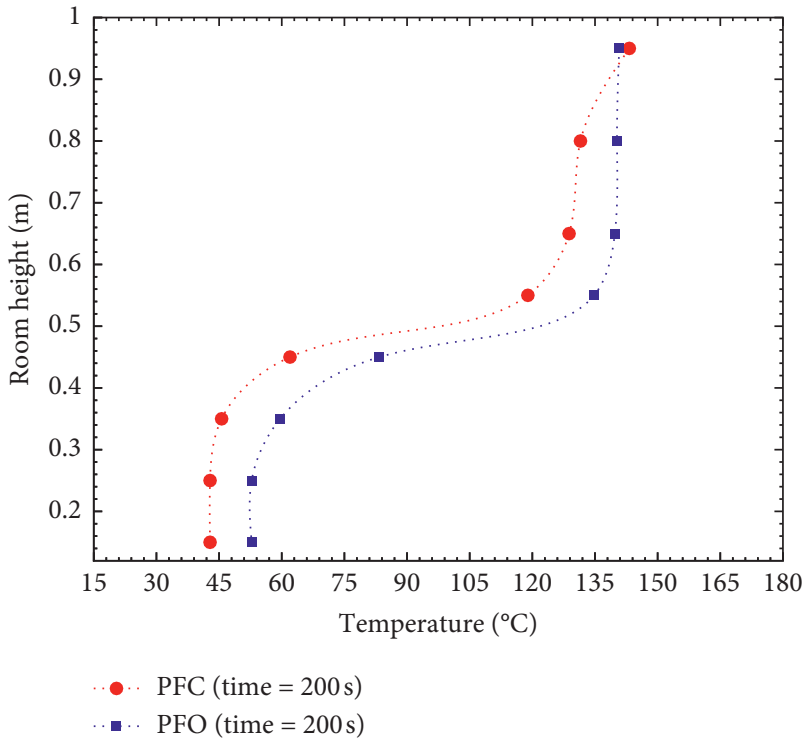

(b)

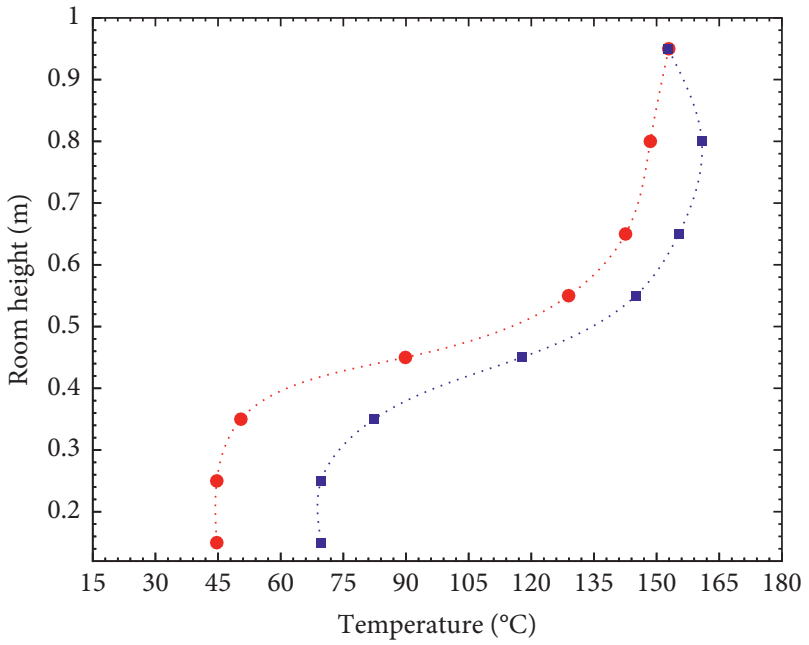

-. $\quad$ PFC (time $=300 \mathrm{~s})$

. $\cdots$ PFO (time $=300 \mathrm{~s})$

(c)

Figure 15: Continued. 


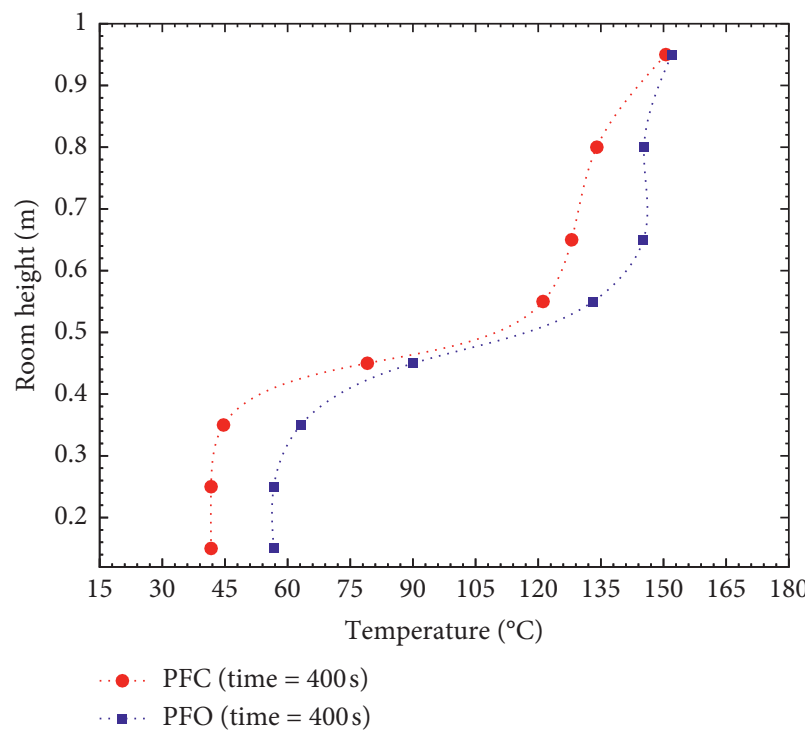

(e)

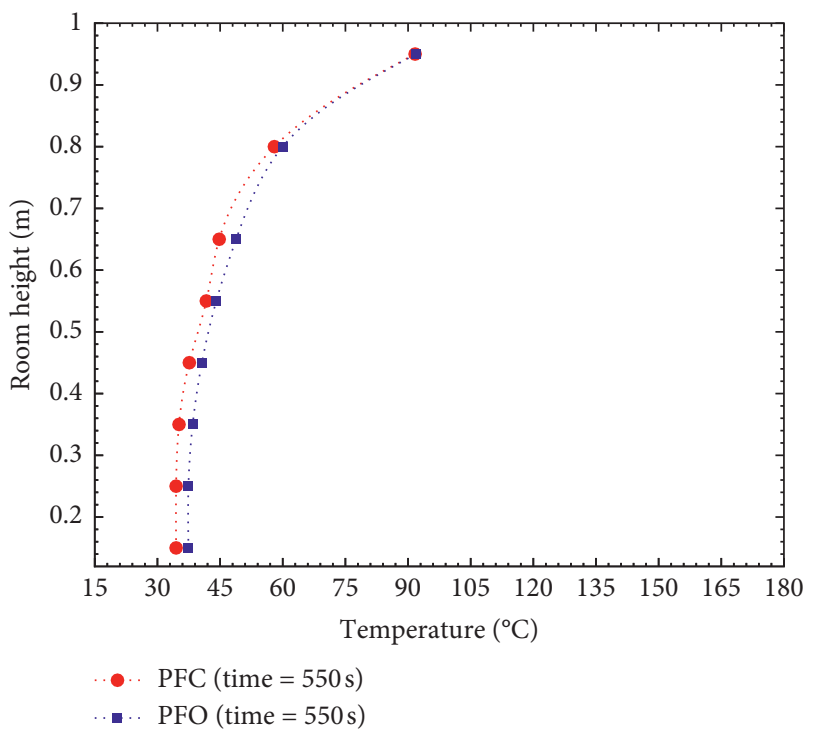

(f)

Figure 15: (a) Profiles of temperature in both configurations at time $t=5$ seconds. (b) Profiles of temperature in both configurations at time $t=200$ seconds. (c) Profiles of temperature in both configurations at time $t=250$ seconds. (d) Profiles of temperature in both configurations at time $t=300$ seconds. (e) Profiles of temperature in both configurations at time $t=400$ seconds. (f) Profiles of temperature in both configurations at time $t=550$ seconds.

TABLE 3: Substantial differences observed between both compared fire tests.

\begin{tabular}{lcc}
\hline & PFC configuration & PFO configuration \\
\hline Global mass loss rate & $2.93 \times 10^{-4} \mathrm{~kg} \cdot \mathrm{s}^{-1}$ & $2.62 \times 10^{-4} \mathrm{~kg} \cdot \mathrm{s}^{-1}$ \\
Peak temperature of hot gases & $140^{\circ} \mathrm{C}$ & $120^{\circ} \mathrm{C}$ \\
Production of ghosting flames & No & Yes \\
\hline
\end{tabular}

transported to the exterior one portion of heat to be transferred to the burned gases rising to ceiling. On the other hand, when the door and the window are not opposite, there is no air flow passing through the flame. That explains the difference in temperature $\left(\Delta \mathrm{T} \approx 20^{\circ} \mathrm{C}\right)$ observed during full development of both configurations (Figure 12).

\subsection{Influence on the Temperature of the Ceiling Hot Gases.} During compartment fire, in addition to the heat release rate of combustion process, the produced toxic gases and soot particles will accumulate in the upper parts of compartment forming a layer of hot gases. These hot gases are at the origin of most deaths recorded during fire incidents. Because of their easy deployment, the latter not only transports heat and therefore fire to other compartments but also pollutes the interior environment of the room. By reducing visibility in the compartment and making the inner air unbreathable, that situation is the cause of death by asphyxiation that met occupants of the building. All thermocouples installed under ceiling thus made it possible to follow the change of these burned gases temperature during fire on each studied configuration. Figures 13 and 14 present the average profile of temperature over time of hot gases under the ceiling of both configurations. In these figures, various shades concerning the development of fire in compartments having this kind of arrangement of openings have been noted. These differences between behaviour of fire in each configuration are observed during the three phases of fire. Indeed, duration of growth phase is substantially equal on both configurations, i.e., 200 s. After this ignition and growth phase, it is the full development phase which is characterized by a constant evolution over time of temperature and during which a gap is also observed on the peak temperature reached by hot gases at ceiling. In fact, on the PFC configuration, this maximal temperature is equal to $140^{\circ} \mathrm{C}$ while on the $\mathrm{PFO}$ configuration, it is $120^{\circ} \mathrm{C}$.

As observed by Dhurandher et al. [29], the vertical gas layer temperature profile for various time intervals increases with time. Indeed, tracing the vertical profile of temperature at different time steps (Figures 15(a)-15(f)) enabled us to highlight the impact of the arrangement of openings on the stratification of gas layers in the compartment. Except the growth (Figure 15(a)) and decay phase (Figure 15(f)), temperature profiles during steady stage illustrate the present of two gas layers in configurations because of the present of a bifurcation point on the curves. Hot gas layer is located in the up part of the room while cool air layer is located in the down part. Transition between both layers is around the half of room height. Therefore, according to 
these profiles, it is observed that temperature of both gas layers is lower in the PFC than in the PFO room. That decreasing in temperature for the PFC room is due to the fact that both openings are not opposite, and this involves retention of incoming fresh air inside the room which induces the cooling of gases layers.

According to the above fire tests carried out in these both configurations, several substantial differences have been observed on the behaviour of fire inside the room (Table 3 ). These differences mainly concern the global mass loss rate of fuel, the maximal temperature of burned gases at ceiling, and the production of ghosting flames during fire.

\section{Conclusion}

The present study aimed to carry out an experimental study on the effects of openings (door and/or window) on the behaviour of fire in a compartment. On the other hand, it was about to bring out a comparative study of the behaviour of fire in a compartment according to the disposition of its open window compared to its open door. After a wide experimental measurement campaign performed on two similar rooms of which the open window and the open door are in opposite walls for the first one and are not in opposite walls for the second one, results revealed that the highlighted differences between both configurations are observed on the global mass loss rate of combustible (fire duration) and on the generation or not of ghosting flames. Future works will be focused on the numerical simulation of these experiments in order to investigate about the field of velocities and the contents in $\mathrm{CO}_{2}, \mathrm{CO}$, and $\mathrm{O}_{2}$ inside each configuration.

\section{Data Availability}

No data were used to support this study.

\section{Conflicts of Interest}

The authors declare that they have no conflicts of interest.

\section{References}

[1] Y. V. Nikitin, "Indirect method of estimating a fire pool area in a closed compartment," Journal of Fire Sciences, vol. 17, no. 1, pp. 57-70, 1999.

[2] P. A. Tatem, F. W. Williams, C. C. Ndubizu, and D. E. Ramaker, "Influence of complete enclosure on liquid pool fires," Combustion Science and Technology, vol. 45, no. 3-4, pp. 185-198, 1986.

[3] W. K. Chow, "Studies on closed chamber fires," Journal of Fire Sciences, vol. 13, no. 2, pp. 89-103, 1995.

[4] G. Heskestad, "Fires plumes, flame height and air entrainment," Handbook of Fire Protection Engineering, SFPE, Boston, MA, USA, 2003.

[5] J. Bowen, "Flashover/backdraft explosive situation," Western Fire Journal, vol. 34, pp. 33-38, 1982.

[6] D. T. Gottuk, M. J. Peatross, J. P. Farley, and F. W. Williams, "The development and mitigation of backdraft: a real-scale shipboard study," Fire Safety Journal, vol. 33, no. 4, pp. 261-282, 1999.
[7] J. Wu, Y. Zhang, X. Gou, M. Yan, E. Wang, and L. Liu, "Experimental research on gas fire backdraft phenomenon," Procedia Environmental Sciences, vol. 11, pp. 1542-1549, 2011.

[8] M. C. Fleischmann and Z. Chen, "Defining the difference between backdraft and smoke explosions," Procedia Engineering, vol. 62, pp. 324-330, 2013.

[9] J. G. Quintiere, Growth of Fire in Building Compartments, Fire Standards and Safety, American Society for Testing and Material, West Conshohocken, PA, USA, 1976.

[10] A. Cowlard, W. Jahn, C. Abecassis-Empis, G. Rein, and J. L. Torero, "Sensor assisted fire fighting," Fire Technology, vol. 46, no. 3, pp. 719-741, 2010.

[11] G. Kagou, B. Kola, and R. Mouangue, "CFD studies of the propagation and extinction of flame in an under-ventilated and over-ventilated enclosure," Journal of Taibah University for Science, vol. 10, no. 3, pp. 393-402, 2016.

[12] A. Mbainguebem, R. Mouangue, and B. T. Bianzeube, "CFD studies of soot production in a coflow laminar diffusion flame under conditions of micro-gravity in fire safety," Journal of Taibah University for Science, vol. 11, no. 4, pp. 566-575, 2017.

[13] R. Mouangue, P. M. Onguene, J. T. Zaida, and H. P. F. Ekobena, "Numerical investigation of critical velocity in reduced scale tunnel fire with constant heat release rate," Journal of Combustion, vol. 2017, Article ID 7125237, 12 pages, 2017.

[14] O. Sugawa, K. Kawagoe, Y. Oka, and I. Ogahara, "Burning behavior in a poorly-ventilated compartment fire -ghosting fire-," Fire Science and Technology, vol. 9, no. 2, pp. 5-2, 1989.

[15] Y. Utiskul, J. G. Quintiere, A. S. Rangwala, B. A. Ringwelski, K. Wakatsuki, and T. Naruse, "Compartment fire phenomena under limited ventilation,” Fire Safety Journal, vol. 40, no. 4, pp. 367-390, 2005.

[16] L. Hu, K. Lu, M. Delichatsios, L. He, and F. Tang, "An experimental investigation and statistical characterization of intermittent flame ejecting behavior of enclosure fires with an opening," Combustion and Flame, vol. 159, no. 3, pp. 11781184, 2012.

[17] F. Tang, L. H. Hu, M. A. Delichatsios, K. H. Lu, and W. Zhu, "Experimental study on flame height and temperature profile of buoyant window spill plume from an under-ventilated compartment fire," International Journal of Heat and Mass Transfer, vol. 55, no. 1-3, pp. 93-101, 2012.

[18] J. G. Quintiere, "Fire behavior in building compartments," Proceedings of the Combustion Institute, vol. 29, no. 1, pp. 181-193, 2002.

[19] M. P. Onguene, R. Mouangue, T. J. Zaida, M. Obounou, and F. H. Ekobena, "Building fire: experimental and numerical studies on behaviour of flows at opening," Journal of Combustion, vol. 2019, 11 pages, 2019.

[20] J. Prahl and H. W. Emmons, "Fire induced flow through an opening," Combustion and Flame, vol. 25, pp. 369-385, 1975.

[21] E. E. Zukoski, T. Kubota, and B. Cetegen, "Entrainment in fire plumes," Fire Safety Journal, vol. 3, no. 2, pp. 107-121, 1981.

[22] J. A. Rockett, "Fire induced gas flow in an enclosure," Combustion Science and Technology, vol. 12, no. 4-6, pp. 165-175, 1976.

[23] B. Y. Lemeshko and E. P. Mirkin, "Bartlett and cochran tests in measurements with probability laws different from normal," Measurement Techniques, vol. 47, no. 10, pp. 960-968, 2004.

[24] P. H. Thomas, M. L. Bullen, J. G. Quintiere, and B. J. McCaffrey, "Flashover and instabilities in fire behavior," Combustion and Flame, vol. 38, pp. 159-171, 1980. 
[25] W. W. Yuen and W. K. Chow, "The role of thermal radiation on the initiation of flashover in a compartment fire," International Journal of Heat and Mass Transfer, vol. 47, no. 19-20, pp. 4265-4276, 2004.

[26] J. Zehfuss and D. Hosser, "A parametric natural fire model for the structural fire design of multi-storey buildings," Fire Safety Journal, vol. 42, no. 2, pp. 115-126, 2007.

[27] N. Alan, "Flashover and boundary properties," Fire and Materials, vol. 45, pp. 116-121, 2010.

[28] W. K. Chow, "New inspection criteria for flashover in compartmental fires," Fire And Materials, vol. 23, no. 1, pp. 13-15, 1999.

[29] B. K. Dhurendher, R. Kumar, and A. K. Dhiman, "An experimental study on crib fires in a closed compartment," Thermal Science, vol. 21, no. 3, pp. 1431-1441, 2017. 